\title{
Performing the knowing archive: heritage performance and authenticity
}

Dr. Jenny Kidd, City University London

Abstract

This article presents findings from the Performance, Learning and Heritage project at the University of Manchester 2005-2008. Using evidence from four case studies, it provides insight into the ways visitors to museums and heritage sites utilise their understandings of 'the authentic' in making sense of their encounters with performances of the past.

Although authenticity is a contested and controversial concept, it remains a significant measure against which our respondents have been influenced by the heritage and tourism industries to analyse and critique their encounters with 'the past'. Beyond superficial analyses however, it is noted that many respondents demonstrate more sensitive and nuanced reflections on the museum as an authentic authoritative voice, analyses that were aided by the very fictionality of the mode of interpretation.

Keywords: performance, authenticity, interpretation, heritage

\section{Introduction}

This article outlines a number of findings from the Performance, Learning and Heritage (PLH) research project at the University of Manchester'. This three year investigation sought to further understand one of the more controversial and contested forms of interpretation employed at museums and heritage sites; performance. Although a number of small scale research and evaluation projects (often institutional) have been carried out in this field, there has been little sustained investigation into the use and impact of the various forms of activity which come under the banner of 'museum theatre' or 'live interpretation', and certainly none that have been able to take the longitudinal approach that PLH did. The research team carried out 377 interviews with museum visitors who had encountered interpretive activity explicitly recognised as performance, in order to establish what, if any, remnants of the encounter remained with them over time (up to a year after the event). ${ }^{\text {ii }}$ These conversations, and the data they created, form the basis of the analysis and conclusions that are presented here.

Heritage performance has been defined as 'the use of theatre and theatrical techniques as a means of mediating knowledge and understanding in the context of museum education' (Jackson and Rees 
Leahy, 2005: 304). It includes first and third person live (mostly costumed) interpretation, gallery performance, scripted monologues, and even large-scale living history events. Often performed with educational intent, such presentations (or exchanges) are designed to facilitate engagement between sites, visitors and the various heritages on offer. There is a growing body of knowledge about such forms of interpretive endeavour (see for example Jackson and Kidd, 2010) however this paper does not seek to present a comprehensive overview of the history of practice, the reasons for its use or its ongoing receipt of criticism. Instead, its sole focus is on the dialogue around authenticity that the performances elicited; how did respondents' concepts of authenticity themselves inform the ways in which they understood and made sense of performances? Of course, this represents a number of theoretical and definitional challenges which will be discussed presently.

The PLH project utilised a mixed method case study approach at four very different sites in the UK; the National Maritime Museum, Greenwich; Llancaiach Fawr Manor, South Wales; the Herbert Art Gallery and Museum, Coventry; and the Manchester Museum.ii These sites were chosen to reflect not the complete spectrum of performance activity currently on offer at museums and heritage sites, simply a sampling of it. We also investigated a variety of audience types including school groups, independent visitors and family groups. ${ }^{\text {iv }}$ In coming to an understanding of the kinds of learning that were facilitated through performance, we utilised a number of methodological approaches including interviews and focus groups, questionnaires, filming, audience tracking and action research (commissioning a performance to test emerging findings). ${ }^{v}$ This mix of approaches revealed a wealth of complex data which has been analysed in a number of project outcomes (including Jackson \& Kidd, 2008; 2010). Although our primary emphasis in the analysis was on how learning was being articulated by respondents, it became clear that educative outcomes were often informed by the ways in which audience members assessed and critiqued authenticity in and through performances. ${ }^{\text {vi }}$

\section{Performing heritage and authenticity}

Performances within heritage contexts, more often than not conceived with educational intent, have often been seen as troublingly and crassly fictionalising in their response to the challenges of history (see for example Hewison, 1987). They have also been seen as exemplifying an increased trend toward cultural tourism; one that is seemingly incompatible with historical voracity (according to Laenen, 1989). Yet criticisms of performance as being infelicitous to a fixed heritage surely rely on an assumption that authenticity 'exists' elsewhere in the museum. On the contrary, as George Hein 
acknowledges, museum displays are created out of context by 'fallible and culturally influenced humans' (Hein, 1998: 151, see also Kirschenblatt-Gimblett, 1998 and Samuel, 1994), with objects undergoing forms of 'reconstruction' (such as cleaning or restoration) which render large chunks of that item's past as undesirable. Seeing it as possible (and desirable) to 'reverse the process of history' in this way is, according to Charles Saumarez Smith, a 'species of contemporary arrogance' (1993: 20). Authenticity is not then an inherent quality of an object or experience but something ascribed to it (Rubridge, 1995).

According to Laurajane Smith, the discourse of 'inauthenticity' that surrounds heritage performance is 'entered into as a means to maintain the authority and gravity of expert knowledge' (Smith, 2006: 69). This discourse has resulted in something of a scramble for legitimacy, measured and actualised in approximations of an (often cosmetic) 'reality'. For those involved in researching, scripting, taking part in and facilitating performance activity (especially re-enactments), authenticity has become a principal concern and aspiration, indeed we might note, a potential distraction (Hunt, 2004, Tivers, 2002). It has likewise become an important consideration for those consuming such performative responses to the past, namely, audiences (Bagnall, 2003 and as found in this study). It is perhaps easier to imagine that we can observe and critique an explicitly 'staged' authenticity in moments of performance; that they might hold themselves up rather more openly for scrutiny than other frames for the consumption of 'heritage'.

The term 'heritage' remains complex and contested both in the literature and in institutional practice. Although as Robert Hewison recognised in the 1980s it is a 'word without definition' (1987: $31)$, there are a number of assumptions inherent in its continued use.

Heritage has traditionally been synonymous with the 'inheritance' of (mostly material) manifestations of 'the past' through generations (see Tivers, 2002). Such material 'treasures' from that past are recognised as having intrinsic, cultural or indeed political value, and undergo continued forms and practices of preservation and presentation. Preservation happens in a number of ways; sometimes privately and behind closed doors, but often publicly and on behalf of the 'nation' vii In recent years, it has become a harder practice to justify, with questions being asked about ownership, authority and the tangibility of artefactual heritages. Presentation, and of course representation, have become trickier practices also, the politics of interpretation opening up myriad competing concerns, agendas and responsibilities for consideration. 
Consequently, we have seen more nuanced understandings of 'heritage' emerge in recent years, placing less emphasis on material culture per se, and more emphasis upon the (many) stories these materials can manifest and inspire. Objects become a starting point not an end in and of themselves, and heritage becomes reconceptualised as a 'process' of passing on and receiving memories, not just the artefacts themselves (Smith, 2006). As such, it inevitably becomes a site of struggle; these stories may be contradictory, controversial and contested within and between cultures and communities. The new museology movement (since the 1970s) has been concerned with recognising not only the multiple nature of 'texts' and the transience of 'history', but also the assumptions inherent in any quest for 'truth' and for 'authenticity' (Bendix, 1999; Rubridge, 1995; Vergo 1989). This can make various methods of interpretation used at museums and heritage sites problematic, but equally can be seen as a liberation from the tyranny of an ordered, onedimensional, fixed - yet still fictitious - 'past'. viii

The idea that museums are performative spaces in and of themselves is by no means new and the idea that museum visitation takes on elements of performance is also well founded (KirschenblattGimblett, 1998; Bagnall, 2003; Smith, 2006; Pearson \& Thomas, 1994; Illeris, 2006). We might introduce Richard Schechner's notion of 'as' performance (as opposed to 'is' performance) as a means of articulating that development. Thinking of an event, location or experience 'as' performance means that we can consider elements from a different angle; to conceive of them as responsive processes that change over time and in response to other factors (Schechner, 2002: 41). We can then consider the ways in which such events differ from or complement activity that 'is' performance. Within a site such as a museum, we begin to see how blurred activity becomes. Think for example of the guided tour, which we might conceive of 'as' performative even if we do not recognise that it 'is' performance (in the traditional, staged or bounded sense). It is conceivable then that the museum is a 'playframe' where 'all messages and signals are recognized as "in a certain sense not true"' (Carlson using Gregory Bateson, 1996: 35).

As is indicated above, and as will be seen, there is perhaps scope for a more considered response to the challenge heritage performance presents to the objective knowing archive that the museum has come to represent.

Theories of authenticity, as developed over the past forty years, have accompanied the rapid expansion in tourism and activities designed for 'the tourist' to consume ${ }^{\text {ix }}$. Indeed, as noted by Waitt, the 'sale' of authenticity became a principle marketing technique within heritage contexts (Waitt, 1999: 836). Dean MacCannell, in 1976, recognised the desire of tourists for authentic 
experience but noted the difficulty in assessing how genuine such experiences might be.

Highlighting both front and backstage activities (and envisaging a spectrum of activities in between), his notion of an intermediary space of stage setting is of course a useful analogy to performance activity; the term 'staged' never-the-less recurs as an assessment of 'false' authenticity in both literature (Cohen, 1988) and in the responses of our research participants.

Some have advocated that we abandon the term 'authenticity' completely (Reisinger \& Steiner, 2006) as differences in definition, application and assessment seem irreconcilable. However, I utilise the term in this article because it proved a frame within which many of our respondents articulated reactions to performance activity within heritage contexts. It is of course a fantastically complex notion and, according to Reisinger and Steiner, is 'not yet a basic concept' (Reisinger and Steiner, 2006: 65), defying singular definition or criteria for assessment. There are continued links however between authenticity and some sense of 'reality' or 'truth' in the literature; according to Waitt, '[c]onventionally, its definitions involved such terms as accurate, genuine, real, true, or actual' (Waitt, 1999: 836). When it comes to the gaze of the audience or tourist, evaluating authenticity tends to involve 'looking for signs' that construct notions of place, reality and truth that we feel comfortable with (Urry, 1995). Seeking authenticity is then a condition of modern society, and increasingly of tourism:

Since modern society is inauthentic, those modern seekers who desire to overcome the opposition between their authenticity-seeking self and society have to look elsewhere for authentic life (Cohen, 1988: 373).

One place 'seekers' turn to then is the 'past' and its manifestations in the heritage industry.

The concept of authenticity is of course socially constructed (as 'heritage'), and Cohen prefers to configure it as a negotiated one. Selwyn goes further, indicating a differentiation between 'authenticity as knowledge' (cool authenticity) and 'authenticity as feeling' (hot authenticity). In this view, again one that will prove a useful framework for analysis, our responses to heritage are at times emotional, and tied up in our notions of 'self', 'self-hood' and 'Other'. Ning Wang takes this further, citing a need to recognise the existential 'authenticity of Being', and its unique individual analysis and recognition; the search for an 'authentic self' (Wang, 1999).

In these more recent conceptualisations, our relationship with the authentic emerges as interpretive, negotiated and personal, as far from absolute and measurable (Waitt, 1999: 836). This is an understanding of 'the authentic' which I will come to in my analysis. However, as Waitt notes, tourists (including audiences for heritage performance) are less likely to recognise authenticity in 
these terms; happier with the 'true-false continuum', and seeking 'accuracy'. For this reason, it is with seemingly more objective analyses of authenticity that I will start.

In the final analysis, I underpin my approach with a consideration from Regina Bendix:

"The crucial questions to be answered are not "What is authenticity?" but "who needs authenticity and why?" and "how has authenticity been used?" (Bendix, 1997: 21)

Although in Bendix's assessment there is no singular answer to those questions, it is my aim to use them as a point of departure; to look at the ways in which audiences for heritage performance turn to authenticity as a tool and a vocabulary for making sense of their encounters with the past, as opposed to analysing how successful or 'true' their analyses might be. Discussions are illustrated with quotations from across our four case studies. ${ }^{x}$ It will be demonstrated that audiences are practised in making assessments of performance (indeed their engagement with 'heritage' more broadly) in terms of authenticity, and are well-versed in the rhetoric around the 'authentic'. However, there is also, on occasion, a unique space being opened up for audiences to explore the complexity, density and multiplicity of heritage in ways that render their individual analysis of 'the authentic' a more nuanced and useful aid to meaning making.

\section{Articulations of authenticity in PLH}

It was one of the major findings of the research project that performance often helped visitors come to a more intricate understanding of the past and the complexities inherent to the particular subject matter, and individual analyses related to the authenticity of an encounter as a whole were important in this process. On occasion however, such analysis could also become a distraction, one instance of perceived inauthenticity becoming a primary focus (indeed an irritant) that proves an insurmountable hurdle in the meaning making process.

In the following sections, a number of audience responses are used to explore the analyses of authenticity that our respondents willingly performed. I refer explicitly to some of the themes raised in the previous section; namely Cosmetic, Staged, Object, and Hot authenticity. However, rather than focusing on the accuracy of audience responses I hope to demonstrate audience members often engaged in more nuanced utilisation of their critique. 


\section{1. 'Cosmetic' authenticity}

As recognised by MacCannell and Cohen in their studies, it was common for our respondents to use seemingly objective criteria in their analyses of the authentic (in initial terms at least). Museum visitors have been sold heritage encounters in these terms for many years (and heritage performance is no exception), and respondents were keen to demonstrate an awareness of discourse around authenticity and the necessity (as they perceived it) of accuracy in presentation. Faithfulness to narratives of history which are practised and familiar proved of great value to our participants, who did not question the existence of an objective and 'real' past, or its given as an aspiration. Our respondents were well versed in arguments that privilege the authentic over its necessary other, the fake (indeed these arguments are often well-rehearsed in site promotional materials and rhetoric) ${ }^{\mathrm{xi}}$

It was very authentic. They hadn't deliberately staged it. [CS2_S_PP3]

This notion of 'the stage' is one I will come back to, but worth noting here its set up as oppositional to a supposedly objective authentic past.

It was often in terms of costume, language, and the authority of the material presentation that authenticity was initially and explicitly addressed:

Mr Pollard's talk was very illuminating... His pictures were carefully labelled and organised which gave them more authenticity than Kurt's book of information and pictures that had bits falling out and water marked (CS3_observations)

You're like thinking, "Right: I could actually be here, maybe, in the past". Then you see that radiator and you think, "No, it's gone. I'm not there anymore". [CS2_S_PP3]

Such analysis of the authentic is unsurprising given the dialogues that surround heritage interpretation more broadly, and given the findings of those such as Cohen who have suggested that individuals are given to assessment along relatively superficial criteria. They are, in Reisinger and Steiner's terms, being 'theoretical' in their assessment of their experiences, and 'open to what is only so long as it fits their idea of what is' (Reisenger \& Steiner, 2006:79. This kind of approach, they go on to say, reflects a need for control over experiences, and can indicate an inability to be open to 
more genuinely authentic experiences which come with participation, trying new things and exploring.

Beyond this initial analysis however, the research began to unearth more nuanced reflection, complicating debates around the extent to which authenticity can be 'staged' or indeed 'stage managed'.

\section{Staged authenticity}

After encountering performances, our respondents very often talked of having an increased sense of what 'the past' might have been like, and the number of allusions they make to this does not diminish over time (in conversations up to one year after the event). Respondents - for the most part - were under no illusions that what they saw was a dramatic presentation of sorts, but felt it uniquely enabled them to mentally inhabit, in the moment of performance at least, another temporal location. These memories often acted as hooks upon which other, more factual, information hung. This ongoing engagement with a 'past' was partly enabled through visitors' experience of sites as 'sets', and artefacts as 'props'; the performative nature of the museum is thus more than apparent to them: $:^{\text {xii }}$

Well, I like performances when they are in a place where they have actually got things going on around the stories they are telling. [CS1_I_PP3]

I think you felt closer to what actually went on than you do in class, reading the textbook and answering questions. [CS4_S_PP2]

Comments on the museum as setting for performance often focused simultaneously on the sense of place provided (a physical and intellectual link to the past), and a desire for 'displacement' (to be taken out of the reality of the museum, its familiarity and sets of expectations into that past). Museums are simultaneously 21st century spaces (with shops and cafes) and places steeped in the heritage(s) they seek to interpret. This 'doubleness' (Carlson 1996: 80) helps enable 'two contradictory realities' to be 'simultaneously in play' during performance (Schechner, 2002: 124, see also Jackson, 2000). Our respondents evidenced a willingness to suspend their disbelief and engage playfully with the 'past' on offer; the museum as a 'playframe' becomes apparent: : $^{\text {iii }}$ 
RESP 1: That one, they were using the area, like when they were using the ship, the part of the museum that was like that, they used that as the ship. You could actually see what was going on. So, even though you know it's not a ship, it's quite nice.

RESP 2: It looks quite like it.

RESP 3: Well, it is; you just have to imagine it. ( LAUGHS ) [CS4_S_PP2]

It was important to our respondents that sites were not 'stages' (in a traditional, static sense), none the less, use of the words 'theatrical' and 'dramatic' was common in making sense of the space and their experience within it.

In one sense, to use MacCannell's differentiation, performance activity (when clearly identified as such) is a purely front stage activity, one which is explicitly and unabashedly touristic and prescribed. But on occasion, research respondents showed willingness to question the ways in which this prescription was being offered, to defy uncritical acceptance of the presentation being offered and to seek a 'back stage'. In participatory performance especially, this was something that they could seek (or even demand) in the moment; asking difficult questions, posing other points of view, or outright rejection of the narrative on offer. In this sense the explicit fictionality of drama can reveal questions that need to be asked about the sites interpretation more broadly :

There is little things that worry me slightly, for example when he was bringing up people to be the English fleet and the French and so on, that it was sort of, it was entertaining and humorous, which of course the real ... wouldn't have. [CS1_F_PP1]

Evidenced here is a quality common to a significant number of our adult respondents; a desire to see performers, and by extension institutions, addressing the singularity of their narratives. We have seen in the research that performance can (when designed to do so) usefully start the process of recomplicating the heritage in question:

it makes you realise that something that you might just be putting a paragraph in your essay about, there is a lot more to it the deeper you go. So don't always just, you know? If you read one paragraph in a book, don't just translate that across, because there might be more to it. [LFM_S_PP3_139] 
RESP: Before the play I couldn't understand why people did it, but once we had that scene where we asked him questions and he gave answers, you start to understand why they did it. It was still wrong, but you understood the motives behind it; they weren't just cold hearted. They actually had reasons for doing it and stuff.

INT: And do you think that that's important...

RESP: Yeah, 'cause if you're trying to persuade someone against it, then if you use the other person's arguments, then it makes your arguments stronger. So that's good.

[MM_S_PP2_154]

Most locations (for museum theatre presentations especially) are only temporarily theatricalised through performance, and their quick return to the normality of the museum even helps to highlight the transience of history and the impermanence of the people and stories that constitute it. In this sense, the staging of a heritage in an explicitly performative framework can help visitors to question their ideas about what constitutes authenticity, and even authority within the museum space.

As we have started to see, performance can occupy a number of liminal spaces and begin to facilitate their exploration ${ }^{\text {xiv }}$; frontstage/backstage, past/present, public/private, place/displace, active/passive, museum/theatre. Our respondents were necessarily active in their negotiation of these juxtapositions, and more explicitly so than they often were in encounters with other forms of interpretation (which on occasion they readily dismiss as 'dry', 'static' and 'predictable'). This was true for their engagement with objects also.

\section{Object authenticity}

Artefacts were perceived by our respondents as an integral part of an historical encounter and a demonstrably important part of the narrative of any museum visit. The way that objects are incorporated in performance thus impresses upon audience members, and they often become readily accessible as 'artefactual memories' (Urry, 1996), and witnesses to history:

'Cause that was held up and put in someone's hand and they said what it was.

Whereas, if that was in a display cabinet, you're going to look at it and think, "I can't be bothered to read that next to it". [CS4_F_PP1] 
... you know, the ring? They hold it up, it gives it feeling, aptitudes and values in quite a different way, I think... seeing things that actually came from the slave trade: that was a very significant moment. [CS4_I_PP1]

Interestingly, at other times objects were taken for granted within the narrative, becoming almost incidental as 'props':

they were using props from the museum to kind of relay the story. [CS4_I_PP3]

In Catherine Palmer's research, physical and material elements were identified as key signifiers of the historically authentic, they 'endure', which enhances their 'power and potency', and the survival of that which they represent (Palmer, 2003: 442). Our respondents had learned to have a respect and awe for any 'real' objects encountered, which is revealing of the ways in which prior visits to museums and historic sites have been framed. There was thus much discussion amongst research participants about the 'real' versus the 'replica'. Younger participants especially do not want to be caught out accepting without question something that later turns out to be 'fake':

I bet they don't even make those candles, or those spoons, or those cups, I don't believe that. [CS2_S_PP2]

The object thus remains unquestioned and legitimised evidence of, indeed is synonymous with, a singular heritage which is otherwise difficult for our respondents to access. As Urry attests however, a past assessed and evidenced in these simple terms 'partly obscures the social relations and struggles which underlay that past' (Urry in McDonald and Fyfe: 52).

The variation in responses to objects in performance is not easily reconciled. The primacy of the artefact in recollections is perhaps no surprise given the reification of the object that often occurs at such sites (a trend carried through into site literature and promotions, even souvenirs). ${ }^{\mathrm{xv}}$ Deetz recognises that 'things have a special kind of immediacy' (Deetz, 2005: 375), yet, as Riegel says, in the traditional museum narrative 'It is the visitor who is in motion, and the objects, and by implication the relationships they embody, are all curiously lifeless' (Riegel, 1996: 86). Objects are a taken-for-granted means of 'accessing' the past, yet their use in performance requires different forms of identification; a recognition of the collision between their role as perceived objective manifestations of knowledge and as 'things' whose use value and/or tangibility is being 
demonstrated: they are 'alive'. Rather than being organised solely within conceptual frames (as in the exhibition, Kirschenblatt-Gimblett, 1998), their framing is now demonstrably performative. This opens up new and exciting avenues for the exploration of their multiple significations. We noted in the research that when an audience had to work harder with artefacts in order to make meaning (holding, using, critiquing or even making objects), they became a more tangible and useful legacy of the site visit.

\section{Hot authenticity}

It is not only material aspects of the heritage offer which enable a sense of the past to be engendered. The importance of individual entry narratives in the meaning making process cannot be overstated (Falk, 2006). For Lisa Roberts (1997) the museum narrative itself is crafted by individuals based on who they are and what they think. This we saw in evidence with our respondents. The following represents one person's ongoing narrative in this regard, the first quote is from the first follow up interview, the second is from an interview ten months later:

... it just so happened that one of the programmes was opened ... and the choreographer was a lady called [OM], who was actually my dancing teacher ... So there were lots of personal memories really. [CS3_I_PP2]

...there were the photographs and the other things they'd collected which we saw at the beginning - they certainly brought back memories of people around at the time ... it was fun to see all that [CS3_I_PP3]

Here, we see a very particular and personal past being evoked through the performance, one that is unique to this respondent, and has lasting impact. ${ }^{\text {xvi }}$ As Chris Ford says in his discussion of museum theatre, this is far from unusual:

Identification with characters, events, situations, thoughts and feelings by the audience is the very essence of theatre and storytelling, and I suggest that no matter how factually correct a theatre presentation might be, there is likely to be an element of personal engagement and interpretation present as well. (Ford in Blais, 1997: 45)

A sense of the past is thus greatly facilitated in performances that strike a chord with visitors own memories and experiences (their biographies become 'sources' for 'emotional mapping' according 
to Gaynor Bagnall, 2003: 91); and perceptions of the authenticity of the story recounted are aided by the authenticity of the feelings and memories engendered. This is a phenomenon recognised by Gaynor Kavanagh in her positioning of museums as dream spaces:

'...the process of remembering can be a very individual matter, a defining part of the self. Whether moved to anger, tears or sheer unadulterated boredom, the position of self within that response is undeniable' (Kavanagh, 2000: 4)

She goes on to add that an understanding of this 'becomes essential to appreciating how and indeed whether museums communicate'. . $v i i^{\text {The }}$ There is nothing inevitable in this process of locating the self within (or indeed outside of) the heritage on offer, but it was certainly true in the research that an ability to empathise with or feel ownership over the narratives being portrayed (wherever these feelings stem from) made that sense of the past more urgent, tangible and, for our respondents, memorable. In this sense, it can be seen that the museum is indeed communicating:

I felt really sad for those people. You really felt what they were feeling, if you were there. If you were one, you felt it. [CS4_S_PP2]

I thought it was quite accurate, the consequence is that it may have been uncomfortable for some, but that was the reality of the day. [CS4_I_PP2]

It put us in the place of the family, because we had to think about how to defend the house, with all the weapons and so it is different than just being on the outside and watching it, because you have to think for yourself and do it. [LFM_S_PP3_123]

There was a feeling that (especially when interpreting perceived difficult and sensitive histories) to stop short of providing 'hot' authenticity of feeling is to fail to legitimise the performance endeavour:

...it shouldn't spare people from the violence, it isn't something like a computer game it is an actual thing that happened. In other words you shouldn't patronise people by assuming that they can't cope with watching something horrific. If they can't, well they'll leave won't they? [CS4_I_PP3] 
Acknowledging this complexity not only adds to the process of knowledge construction, but is key to enabling a questioning of and reflection on assumptions about where and who constitutes authority. This was especially powerful in performances utilising more than one voice. The immediacy of the arguments being played out in front of audiences through multiple voices/characters (not necessarily multiple actors) was something that participants found shocking, illuminating, and above all, memorable. In such performance, the 'totalising narratives' (Hutcheon, 2002) of past interpretations began to give way to an intricate exploration of the composition of heritage. As Bradburne recognises, this is more in tune with the reflective museum of the twentyfirst century:

It is in the spirit of the piazza that the museum must be a public forum, a place where all voices can be heard, differences explored, similarities compared. To fulfil its role in the next century, the museum must wean itself from the need to dispense the truth from on high - it must give up being top-down. The museum does not make culture, it does not shape identity, it does not have all the answers. The museum plays a potentially far more important role. It preserves culture, registers identity - it has questions. (Bradburne, 2000: 391)

\section{Conclusions}

The PLH research demonstrated that performance can foster more nuanced understandings of the heritages on offer at a range of different sites, and that with certain reservations, it should be more

readily accepted into the catalogue of interpretation techniques that sites use. ${ }^{\text {xviii }}$ Audiences respond positively (with a few notable exceptions) to the opportunities that performances present to suspend belief, empathise with peoples' other than themselves, engage with a 'past' and make it 'real'.

As knowledge is perspectival, so is any account of or aspiration to authenticity. None-the-less, perceptions of 'authenticity' remain crucial to individuals' meaning making processes, and a quality that they have become accustomed to making judgements about based no doubt on their understanding of cultural authority - where it exists and how it is evaluated, in and by the museum. However, usefully complicating the meaning making process through the inclusion of multiple voices, and more challenging conceptualisations of what 'heritage' is, enabled our respondents to explore the physicality, multiplicity and complexity of the past in ways that felt new, shocking and memorable. In these moments, their active questioning of the performance's 'authenticity' became an aid to meaning making rather than a hindrance. 
Tom Selwyn, in introducing his book on the tourist image, uses John Urry's radical proposal to rethink the tourist gaze in order to unravel the notion of singular authenticity:

there is no one simple 'authentic reconstruction of history... [for] all involve various kinds of accommodation and reinterpretation' and that one important consequence of all this is the 'democratisation of the tourist gaze' (Urry, 1990 in Selwyn, 1996: 19)

The responses from research participants above hint that we may be beginning to see this in evidence. When it comes to the interpretation of heritage - particularly those histories perceived as difficult or challenging - upping the stakes, taking some (well calculated) risks, and engaging audiences in dialogue through performance can engender a healthy questioning of cultural authority, an understanding of the knottiness of the past, and result in less superficial analyses of the 'authentic'.

Ames, M. A. 2005. "Museology Interrupted" in Museum International No 227, Vol 57, No 3, 2005 Oxford: Blackwell, 44-51

Bagnall, G. 2003. 'Performance and performativity at heritage Sites' in Museum and Society , 1(2) 87103

Bendix, R. 1997. In Search of Authenticity . Madison : University of Wisconsin Press.

Bradburne, James. 2000. 'The Poverty of Nations: Should Museums Create Identity?' in Fladmark, (ed) Heritage and Museums: shaping national identity. Shaftesbury: Donhead. pp. 379-91.

Carlson, M. 1996. (2004 edition). Performance: A Critical Introduction. London and New York: Routledge.

Crane, S. (ed.) (2000). Museums and Memory. Palo Alto, CA: Stanford University Press .

Deetz, J. 2005. 'A Sense of Another World: History Museum and Cultural Change' in Carbonell, B.M. Museum Studies: An Anthology of Contexts Oxford: Blackwell Publishing.

Ford, C. 1997. 'Theatre as a learning medium in museums' in Blais, Jean-Marc, ed. The language of live interpretation: animation in museums. Hull, Quebec : Canadian Museum of Civilization. 
Hein, G. 1998. Learning in the Museum. London : Routledge.

Henning, M. 2006. Museums, Media and Cultural Theory. Open University Press.

Hewison, R. 1987. The Heritage Industry. London : Methuen

Hooper-Greenhill, E. 2005. 'Changing Values in the Art Museum: Rethinking Communication and Learning' in Carbonell, B.M. Museum Studies: An Anthology of Contexts Oxford: Blackwell Publishing.

Hooper-Greenhill, E. 2007. Museums and Education: Purpose, Pedagogy, Performance. Oxon: Routledge

Hunt, S. J. 2004. 'Acting the Part: 'living history' as a serious leisure pursuit' in Leisure Studies Vol. 23, No. $4,387-403$.

Hutcheon, L. 2002. The Politics of Postmodernism. London: Routledge.

Illeris, H. 2006. 'Museums and galleries as performative sites for lifelong learning: constructions, deconstructions and reconstructions of audience positions in museum and gallery education' in Museum and Society March 20064 (1) 15-26

Jackson, A.\& Kidd, J. 2010. Performing Heritage. Manchester: Manchester University Press.

Jackson, A. \& Kidd, J. 2008. 'Performance, Learning and Heritage' final report, University of Manchester. CATR.

Jackson, A. \& Rees-Leahy, H. "Seeing it for Real? Authenticity, theatre and learning in museums" Research In Drama Education Vol 10, No.3, November 2005. pp. 303-325.

Jackson, A. Johnson, P. Rees Leahy, H. Walker , V. September 2002. Seeing it for Real: An Investigation into the effectiveness of theatre and theatre techniques in museums. University of Manchester. CATR.

Jackson, A. 2000. 'Inter-acting with the past - the use of participatory theatre at museums and heritage sites' in Research in Drama Education , Vol. 5, No.2

Kavanagh, G. 2000. Dream Spaces: Memory and the Museum. Leicester: Leicester University Press 
Kirshenblatt-Gimblett, B. 1998. Destination Culture: tourism, museums \& heritage. Berkeley : University of California Press.

Laenen, M. 1989. 'Looking for the Future Through the Past' in Uzzell, David, 1989, (editor) Heritage Interpretation Volume 1. London: Belhaven.

MacCannell, D. 1976 (1999 edition). The Tourist: A new theory of the leisure class. University of California Press: Berkeley.

Macdonald, S. \& Gordon F. eds. 1996. Theorizing Museums: Representing Identity and Diversity in a Changing World. Cambridge, Massachusetts : Blackwell

Palmer, C. 2003. 'Touring Churchill's England: Rituals of Kinship and Belonging' in Annals of Tourism Research. Vol. 30.2 pp.426-445.

Pearson, M. and Thomas, J. 1994. 'Theatre/Archaeology' in The Drama Review . Winter 1994 v.38 n4 p133(29)

Reason, M. 2004. 'Theatre Audiences and Perceptions of 'Liveness' in Performance' in Particip@tions Vol.1 Issue 2

Reisinger,Y. \& Steiner, C.J. 2006. 'Reconceptualising Object Authenticity' in Annals of Tourism Research. Vol. 33.1 pp.65-86.

Riegel, H. 1996. 'Into the heart of irony: ethnographic exhibitions and he politics of difference' in McDonald, S and Fyfe, G. 1996. Theorizing Museums. Oxford: Blackwell Publishing

Roberts, L. C. 1997. From Knowledge to Narrative: Educators and the Changing Museum Washington and London : Smithsonian Institution Press.

Rubridge, S. 1995. 'Does Authenticity matter? The case for and against authenticity in the performing arts' in Campbell, P. Analysing Performance: interpretations, issues, ideologies. Manchester : Manchester University Press

Saumarez Smith, C. 'Museums, Artefacts and Meanings' in Vergo, P (editor). 1993 ( $1^{\text {st }}$ edition 1989). The New Museology. London : Reaktion Books

Samuel, R. 1994. Theatres of Memory: 1: Past \& Present in Contemporary Culture (London : Verso) 
Schechner, R. 2002. Performance Studies: An Introduction . London : Routledge.

Selwyn, T. 1996. The Tourist Image: Myth and Myth Making. Wiley.

Smith, C. 'Museums, Artefacts and Meanings' in Vergo, P (editor). 1993 ( $1^{\text {st }}$ edition 1989). The New Museology. London : Reaktion Books

Smith, L. 2006. The Uses of Heritage. London: Routledge.

Tivers, J. 2002. 'Performing heritage: the use of live 'actors' in heritage presentations' in Leisure Studies 21 187-200

Turner, Victor, 1982, From Ritual to Theatre: the human seriousness of play. Performing Arts Journals.

Turner, V. 1974. Dramas, Fields and Metaphors: Symbolic Action in Human Society. Cornell University Press: New York.

Urry, J. 1996. 'How societies remember the past', in Macdonald, S., Fyfe, G. (eds), Theorizing Museums, Cambridge, MA: Blackwell. pp.45-65.

Urry, J. 1995. Consuming Places. Routledge: London and New York

Vergo, Peter (ed.) 1989. The New Museology. London: Reaktion Books

Waitt, G. 1999. 'Consuming Heritage: Perceived Historical Authenticity' in Annals of Tourism Research 27: pp.835-962

Wang, N. 1999. Re-thinking Authenticity in Tourism' in Annals of Tourism Research. Vol.26.2. pp. $349-370$

\section{Bibliographical note:}

Jenny Kidd is a Lecturer in Cultural Policy and Management at City University London. Previously she was a Research Associate at the University of Manchester in their Centre for Applied Theatre 
Research. Jenny's research interests include museums, digital media, audiences and their representation. Contact: jenny.kidd.1@city.ac.uk.

\footnotetext{
'The project was funded by the AHRC (from 2005-2008).

ii The 'we' referred to here is the Performance, Learning and Heritage research team: Project Director Prof. Anthony Jackson, full time Research Associate Dr. Jenny Kidd and part time Administrator Ruth Daniel.

iii For further detail of methods used and case study sites see the PLH project report available at www.manchester.ac.uk/plh

${ }^{\text {iv }}$ Much previous work in this area has concentrated solely on school audiences (including work at the University of Manchester, see for example the Seeing it for Real report at http://www.plh.manchester.ac.uk/research/resources/more/pub_seeforreal.htm).
}

${ }^{\vee}$ More can be found about the research questions, aims and methodology at www.manchester.ac.uk/plh

vi There were a number of 'themes' identified in the research data; Visitors and Audiences, Performance, Interactivity and Participation, Learning, and Heritage and Authenticity. This paper deals almost exclusively with the last of these themes.

vii The link between heritage and nation is both frequent and contested (see Bradburne, 2000).

viii There has also been recognition of intangible forms of heritage in the shape of the 2003 UNESCO Convention for the Safeguarding of the Intangible Cultural Heritage initiative. The UNESCO project recognises that many cultures have a range of practices that constitute 'heritage', and often different attitudes toward, and experiences of, material culture (including having it removed or destroyed). Intangible heritages, wherever they occur, are forms of signifying cultural practice which are arguably also important to preserve in some way.

${ }^{\text {ix }}$ For more on authenticity see MacCannell, 1973; Cohen, 1988; Reisinger \& Steiner, 2006; Waitt, 1999; Urry, 1995; Selwyn, 1996; Wang, 1999)

${ }^{x}$ Each quotation has a code which relates to the case study (National Maritime Museum - CS1, Llancaiach Fawr Manor - CS2, Triangle Theatre Company at the Herbert Art Gallery and Museum - CS3 or Manchester Museum - CS4), the type of participant (S-school pupil, I-independent visitor, F-Focus group member), and the period in which the discussion took place (PP1-on the day, PP2-weeks following, PP3- ten months later).

xi ... identifying some cultural expressions or artefacts as authentic, genuine, trustworthy, or legitimate simultaneously implies that other manifestations are fake, spurious, and even illegitimate." (Bendix, 1997: 9)

xii As Urry, 1996 also demonstrates.

xiii As Carlson says, "Whatever the suspension of disbelief visitors bring to these encounters, they are obviously aware of their performative nature" (Carlson, 1996: 109). This does not preclude audience members from being able to actively and vigorously critique what they see.

${ }^{\text {xiv }}$ Victor Turner's concept of liminality is an important one in performance research, see Turner, 1974 and on ritual behaviours and optation in Turner, 1982. 


\footnotetext{
${ }^{x v}$ Ames said in 2005 that 'The dominance of objects in the work of museums also dominates the theoretical imaginations of those working in museums' (Ames, 2005: 45).

xvi See Henning, 2006, for an overview of literature documenting a shift toward more subjective museum 'experience' as being a core orientation for the modern museum.

xvii The museum as communicator is an aspiration identified also in Eilean Hooper-Greenhill (2005).

xviii For more information, see the project report.
} 